\title{
Gain Enhancement of Double-Slot Vivaldi Antenna using Corrugated Edges and Semicircle Director for Microwave Imaging Application
}

\author{
Findi Nur Witriani a, *, Yahya Syukri Amrullah b, Fajri Darwis b, \\ Taufiqqurrachman Taufiqqurrachman $^{\text {b }}$, Yusuf Nur Wijayanto ${ }^{\text {b }}$, Ken \\ Paramayudha $^{\text {b }}$, Elisma Elisma ${ }^{\text {a }}$ \\ ${ }^{a}$ Department of Electronics Engineering \\ Bandung State Polytechnic \\ Jl. Gegerkalong Hilir Ds. Ciwaruga \\ Bandung, Indonesia \\ ${ }^{b}$ Research Center for Electronics and Telecommunication \\ Indonesian Institute of Sciences \\ Komplek LIPI Jl. Sangkuriang Gedung 20 \\ Bandung, Indonesia
}

\begin{abstract}
Microwave imaging, such as images for radiological inspection in the medical profession, is one of the applications utilized in ultra-wideband (UWB) frequency ranges. The Vivaldi antenna is one of the most popular antennas for this purpose. The antenna is utilized because of its simple, lightweight, and compact design, as well as its excellent efficiency and gain capabilities. In this work, we present a high-gain Vivaldi antenna for microwave imaging applications. The proposed Vivaldi antenna is designed using a double-slot structure method with the addition of corrugated edges and a semicircle director aimed at improving the gain. The antenna is designed to operate at frequencies ranging from 3.1 to $10.6 \mathrm{GHz}$. Based on the modeling findings, the suggested antenna attain a bandwidth of $7.5 \mathrm{GHz}$ with operating frequencies from $3.1 \mathrm{GHz}$ to $10.6 \mathrm{GHz}$ for a VSWR of less than two. In comparison to a typical single slot antenna, the suggested antenna provides a substantial boost in gain performance. The increase in gain is proportional to the frequency of operation. The constructed antenna has a lower bandwidth than the simulated one, with operating frequencies of $3.5 \mathrm{GHz}-3.75 \mathrm{GHz}$ and $4.25-10.89 \mathrm{GHz}$, respectively, and useable bandwidths of $250 \mathrm{MHz}$ and $6.64 \mathrm{GHz}$. All these results suggest that the antenna is suitable for microwave imaging applications.
\end{abstract}

Keywords: Vivaldi Antenna, Ultrawideband (UWB), Microwave Imaging.

\section{INTRODUCTION}

In the last decade, studies in microwave imaging have gained significant interest among researchers. The application of microwave imaging, particularly in the medical field, is promising due to its non-invasive characteristic. There are several advantages of this technique over conventional imaging methods such as Xrays and MRI, including being more cost-effective and the signal emitted is non-ionizing. Non-ionizing radiation has sufficient energy to remove electrons or molecules without forming new ions [1]. This radiation can be in the form of electromagnetic waves such as microwaves, ultraviolet light, infrared light, or laser light. For microwave imaging, an antenna with wide bandwidth is needed, namely an ultra-wideband (UWB) antenna [2]. An antenna device can be categorized as ultra-wideband when it has a fractional bandwidth value greater than 0.25 . The most prominent type of antenna that can be utilized for this application is the Vivaldi antenna [3]

\footnotetext{
* Corresponding Author.

Email: findinurwitriani@gmail.com

Received: August 13, 2021 ; Revised: October 11, 2021

Accepted: November 2, $2021 \quad$; Published: December 31, 2021

Open access under CC-BY-NC-SA

(C) 2021 PPET - LIPI
}

Gibson, in 1979, was described as the Vivaldi antenna. This antenna has been studied and applied by many researchers due to its compact and lightweight structure, broadband, and high gain. Vivaldi antennas have been used in many ultrawideband systems, for example, ground-penetrating radar and medical imaging. Many antenna engineers have used Vivaldi antenna to meet UWB requirements for their application, including researchers in [4], who created two antennas, a single slot Vivaldi antenna and a Vivaldi antenna with double slots structure, which were compared to understand the characteristics difference between the two. Based on their study, the utilization of the double slot structure technique can enhance the gain of the Vivaldi antenna.

In another experiment, a design of a coplanar Vivaldi antenna for breast imaging with frequency response improvement was reported [5]. Their proposed antenna design exhibited a wide impeandce bandwidth of more than 138 percent from $1.3 \mathrm{GHz}$ to $7.09 \mathrm{GHz}$, and the VSWR response was improved by using a different design technique. Authors in [6] proposed a miniaturized coplanar waveguide (CPW) fed Vivaldi antenna for microwave imaging applications using various techniques, namely different types of slots and gratings. The CPW feeding approach was chosen for its excellent impeandce matching. The design and simulation of an 
ultrawideband microstrip antenna for breast cancer detection were carried out in [7]. They discovered that the amplitude of E-Field, H-Field, and current density measured in breast tissue without cancer was smaller than those measured in breast tissue with cancer.

Authors in [8] proposed a UWB circular antipodal Vivaldi antenna for translucent radar. They combined Vivaldi antenna with antipodal configuration and circular load for ground penetrating radar using UWB frequency between 3.1 and $10.6 \mathrm{GHz}$. A redesigned hollow side Vivaldi antenna design for microwave imaging applications was studied in [9], with several improvements in the bandwidth, efficiency, and gain performances. During breast image measurement, the antenna is utilized to detect tumor cells in the breast.

Regarding the gain enhancement of Vivaldi antenna, several effective approaches have been introduced in previous reports. Authors in [10] demonstrated that using corrugated edges on the Vivaldi antenna can enhance the gain. The shapes of corrugated edges that were studied are varied, namely triangle and circle. In a more recent publication [11], to enhance the directivity of a double antipodal Vivaldi antenna, Yunpeng Zhang et al. combined corrugated edges with a semicircle director. The goal of utilizing a director is to concentrate all the energy on the end-fire direction. The director was created using a half-spherical dielectric lens in this study. They claim that the suggested antenna's gain is substantially higher than similar antennas described in the literature when employing this approach, particularly at high frequencies.

A Vivaldi coplanar antenna employing a double-slot structure with a semicircle director and corrugated edges is presented in this article. This research aims to increase the gain and directivity of Vivaldi antenna using methods that were introduced in [4] and [11]. To the best of our knowledge, the combination of these methods has not been found in previous publications. In the context of microwave imaging application, a gain enhancement leads to a more focused beam which can increase the object-to-clutter ratio.

\section{ANTENNA DESIGN}

The antenna was created on a Rogers RO4003C substrate with a thickness of $0.813 \mathrm{~mm}, \varepsilon r=3.55$ and tand $=0.0027$. Figure 1.a shows the layout of the proposed double-slot Vivaldi antenna with corrugated edges and a semicircle director, whereas Figure 1.b shows the configuration of a single slot Vivaldi antenna. Table 1 shows the optimal design parameters.

The initial step of the design is to define the tapered slot part of the antenna. The tapered slot of the double slot Vivaldi antenna is made up of four exponential curves: $y a_{1}, y a_{2}, y b_{1}$, and $y b_{2}$, as illustrated in Figure 1.a.

$$
\begin{array}{ll}
y_{a 1}=\frac{1}{2}\left(W s+g \times \exp \left(\ln \left(\frac{W-W s}{g}\right) \times \frac{x}{L s}\right)\right), & (0 \leq \mathrm{x} \leq \mathrm{L}) \\
y_{a 2}=\frac{1}{2}\left(-W s-g \times \exp \left(\ln \left(\frac{W-W s}{g}\right) \times \frac{x}{L s}\right)\right),(0 \leq \mathrm{x} \leq \mathrm{L}) \\
y_{b 1}=\frac{1}{2}\left(W s-g \times \exp \left(\ln \left(\frac{W s}{g}\right) \times \frac{x}{L s}\right)\right), & (0 \leq \mathrm{x} \leq \mathrm{Ls}) \\
y_{b 2}=\frac{1}{2}\left(g \times \exp \left(\ln \left(\frac{W s}{g}\right) \times \frac{x}{L s}\right)-W s\right), & (0 \leq \mathrm{x} \leq \mathrm{Ls})
\end{array}
$$

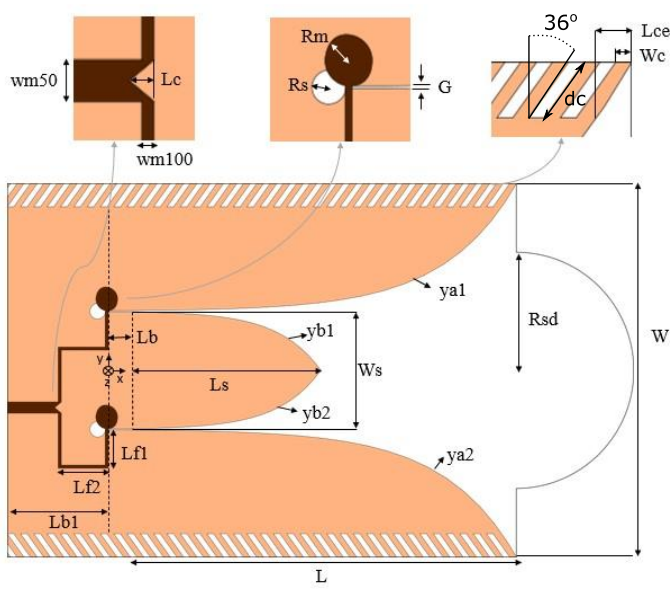

(a)

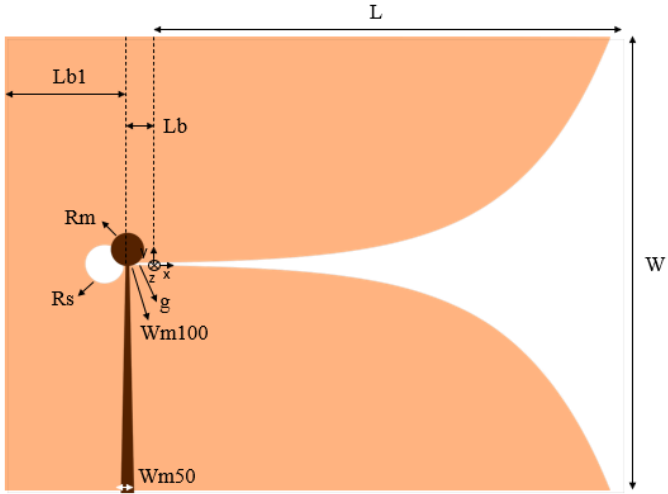

(b)

Figure 1. (a) Structure of double slot Vivaldi antenna. (b) Structure of single slot Vivaldi antenna.

From (1) to (4), there are several parameters used to create exponential curves, namely $W s, G, W, L s$, and $L$. $W s$ is the width of the inner ridge, $G$ is the width of the distance between exponential curves $y_{a}$ and $y_{b}, L s$ is the length of the inner ridge, and $L$ is the length of the antenna without the semicircle. The next step was to design the components for gain enhancement. The corrugated edges were etched to concentrate the surface current on the tapered edge to enhance the gain in the lower frequency range. The numbers of corrugated slots including their width, length, and angle were optimized using CST Studio Suite 2021 for maximum gain and minimum return loss. Lastly, a semicircle director was added to further improve the gain of the antenna.

TABLE 1

STRUCTURE PARAMETERS OF DOUBLE SLOT AND SiNGLE SLOT VIVALDI ANTENNA

\begin{tabular}{|c|c|c|c|}
\hline Parameters & Value (mm) & Parameters & Value (mm) \\
\hline W & 95 & Rs & 4 \\
\hline Ls & 50 & Lb & 5 \\
\hline G & 0.3 & Lb1 & 25 \\
\hline Ws & 30 & Lc & 1.7 \\
\hline L & 100 & Lce & 6 \\
\hline Wm50 & 3.6 & Wm100 & 0.77 \\
\hline Wc & 1.7 & Lf2 & 12 \\
\hline Rm & 3 & Rct & 39.23 \\
\hline Lf1 & 10 & Rsd & 30 \\
\hline Lf3 & 13.76 & dc & 36 \\
\hline
\end{tabular}




\section{RESULTS AND DISCUSSION}

Figure 2 shows simulated E-plane and H-plane radiation patterns at the frequency of $10 \mathrm{GHz}$ to explain the mechanism of directivity improvement in the doubleslot structure, Figure 3 shows fabricated double slot antennas and measured reflection coefficients of simulated single and double slot antennas, and Figure 4 shows gain comparison between single slot and double slot antennas, and Figures 5 and 6 show the radiation patterns of the single slot and the proposed double slot antennas at three samples of frequencies.

At a frequency of $10 \mathrm{GHz}$, the antenna's radiation patterns are simulated on the E-plane and H-plane, as illustrated in Figure 2. To measure the co-polarization, the transmitted reference antenna and the antenna under test were in-plane. Whereas, to measure the crosspolarization, the transmitter and receiver were perpendicular to each other.

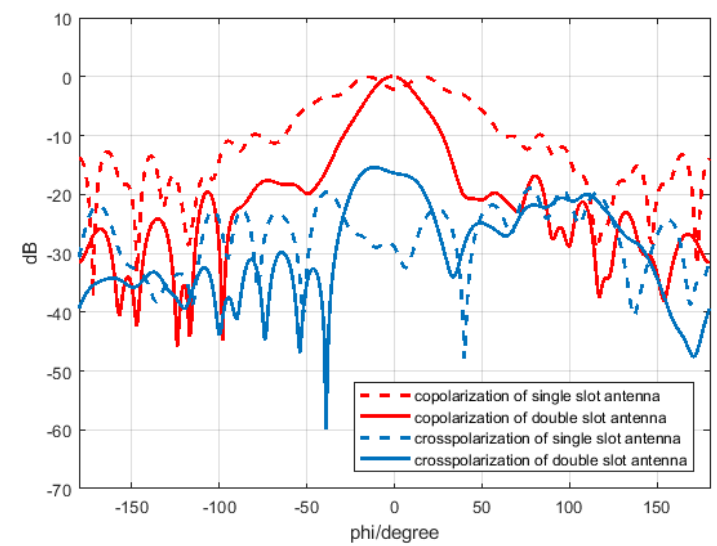

(a)

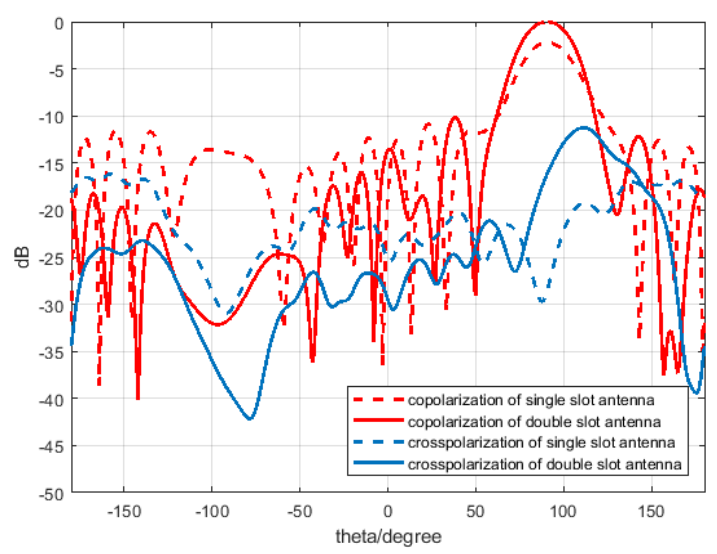

(b)

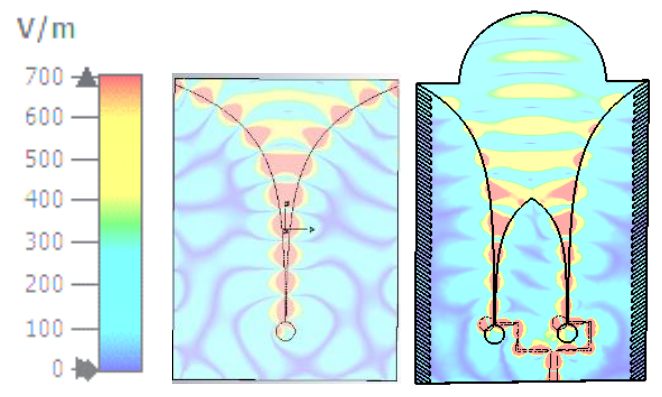

(c)

Figure 2. Simulated results at $10 \mathrm{GHz}$. (a) E-plane radiation pattern. (b) $\mathrm{H}$-plane radiation pattern. (c) E-field distributions in xy-plane.
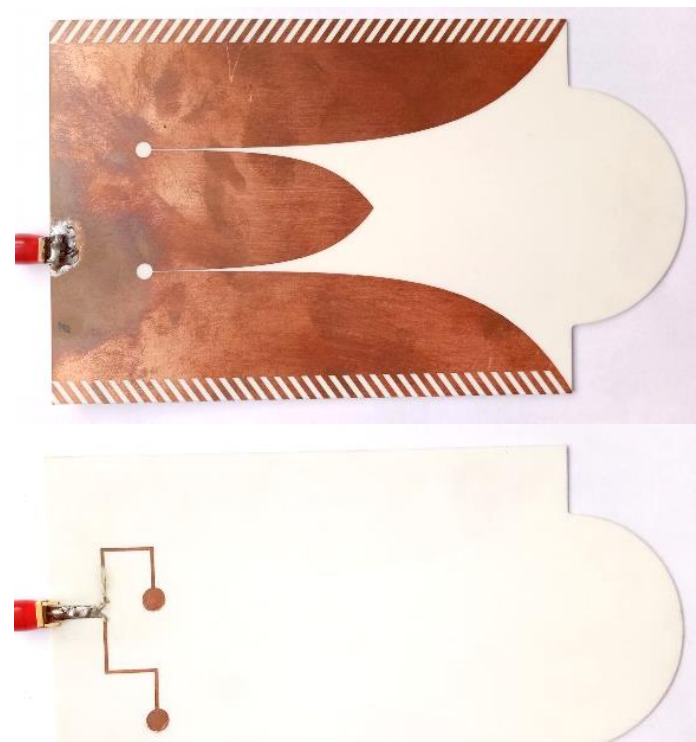

(a)

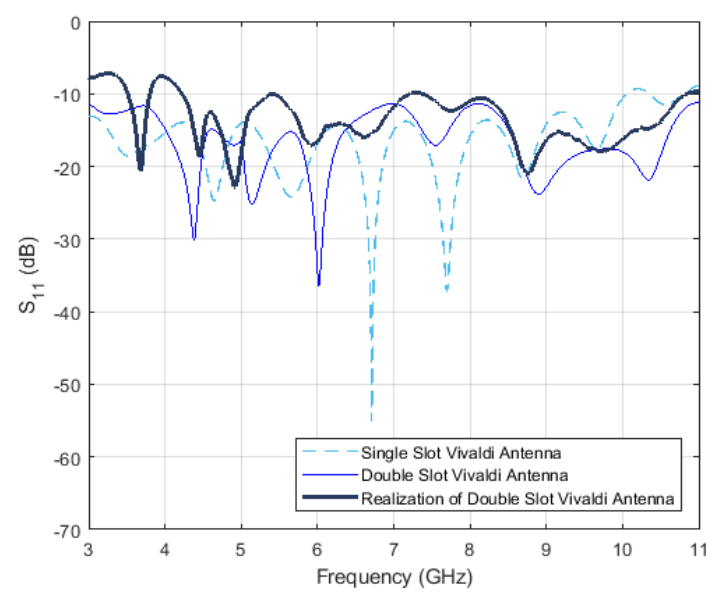

(b)

Figure 3. (a) Photograph of the fabricated double slot antenna, top, and bottom views. (b) Reflection coefficients of simulated single slot and double slot antennas and measured double slot antenna.

The difference between co- and cross-polarization of the antenna is approximately $20 \mathrm{~dB}$ at the main beam, as depicted in Figure 2.a and 2.b. It also can be seen from these figures that the directivity of the double slot antenna is significantly higher than the single slot antenna.

In Figure 2.c , the distribution of the E-field from the single slot Vivaldi antenna is compared with the distribution of the E-field from the double slot antenna. The single-slot Vivaldi antenna produces waves with a spherical shape that almost leads in all directions, implying that the resulting directivity is low. The double slot antenna generates the same waves but is more focused in one direction. Implying that the double slot antenna has better directivity than the single slot Vivaldi antenna, while side lobes are still formed in the simulation of radiation patterns. 


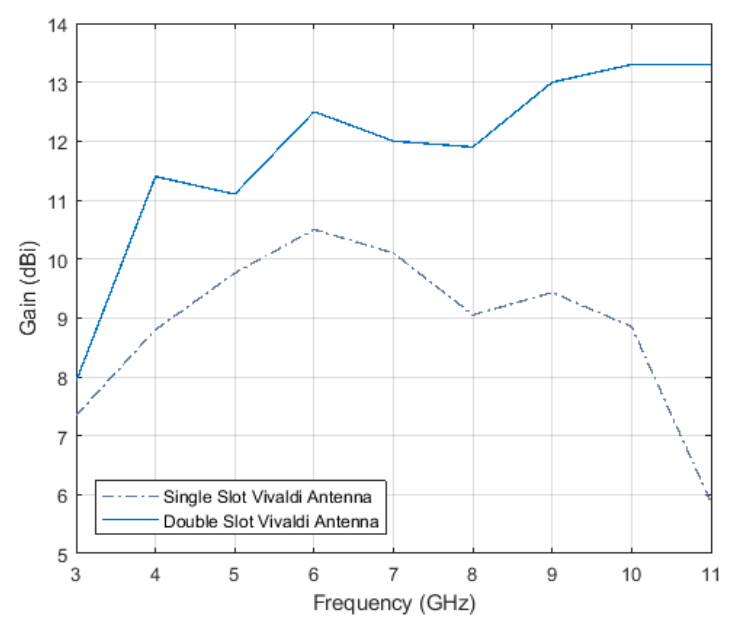

Figure 4. Gain comparison between single slot and double slot antenna.

It is noted that the operating frequency and bandwidth of the single slot Vivaldi antenna have not yet met the required specification, although they are close to $6.93 \mathrm{GHz}$, which is supposed to have a bandwidth of 7.5 GHz. However, compared to double slot antennas, this single slot antenna has a higher return loss of $55.05 \mathrm{~dB}$ for the maximum return loss.

The Vivaldi double slot antenna has met the required specifications, with a working frequency range from 3.1 $\mathrm{GHz}$ to $10.6 \mathrm{GHz}$ or bandwidth of $7.5 \mathrm{GHz}$, and a VSWR of less than 2 for each of these frequencies. The antenna decreased to $36.39 \mathrm{~dB}$ for the highest return loss.
However, on the fabricated antenna, the return loss decreased to $-22.95 \mathrm{~dB}$, with the resulting working frequency also reduced, namely at $3.5 \mathrm{GHz}-3.75 \mathrm{GHz}$ and $4.25 \mathrm{GHz}-10.89 \mathrm{GHz}$, which means the usable -10 $\mathrm{dB}$ impedance bandwidths are $250 \mathrm{MHz}$ and $6.64 \mathrm{GHz}$. This occurred because there was an issue when printing the PCB at the time of realization, specifically a size error in the circular tuning stub on the back of the printed antenna, resulting in less-than-ideal outcomes. The difference between simulated and fabricated tuning stubs can be seen in Figure 7.

From $3 \mathrm{GHz}$ to $11 \mathrm{GHz}$, the radiation pattern of a single slot and double slot Vivaldi antenna is directional, as seen in Figures 5 and 6 . When the frequency is getting bigger, the radiation pattern has many side lobes, and the main lobe is getting wider. The difference between a single slot and double slot Vivaldi antenna radiation pattern can be seen in the gain.

A gain comparison between the two antennas can be observed in Figure 4 and Table 2. It can be seen at a frequency of $3 \mathrm{GHz}$, the increase in the obtained gain is $0.58 \mathrm{dBi}$. At the $4 \mathrm{GHz}$ frequency, the increased gain is $2.6 \mathrm{dBi}$, and at the $5 \mathrm{GHz}$ frequency, the increased gain is $1.34 \mathrm{dBi}$. The gain increment at a frequency of $6 \mathrm{GHz}$ is $2 \mathrm{dBi}$ and at a frequency of $7 \mathrm{GHz}$ is $1.9 \mathrm{dBi}$. Then at the $8 \mathrm{GHz}$ frequency, an increase of $2.85 \mathrm{dBi}$ gain is obtained, while at the $9 \mathrm{GHz}$ frequency, an increase of $3.57 \mathrm{dBi}$ is obtained. At the $10 \mathrm{GHz}$ frequency, an increase of $4.45 \mathrm{dBi}$ is obtained, and lastly, at the $11 \mathrm{GHz}$ frequency, the gain increment is $7.43 \mathrm{dBi}$.

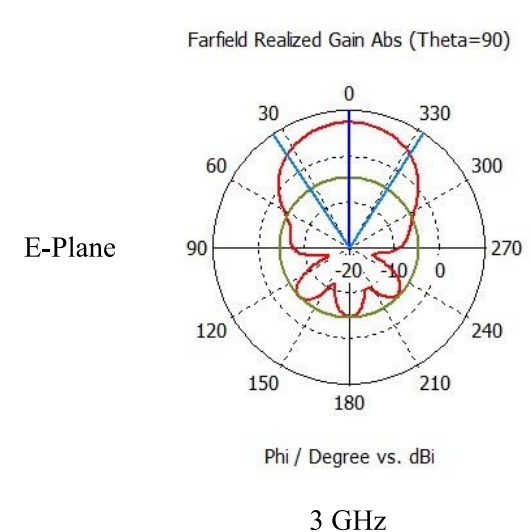

Farfield Realized Gain Abs (Theta $=90$ )

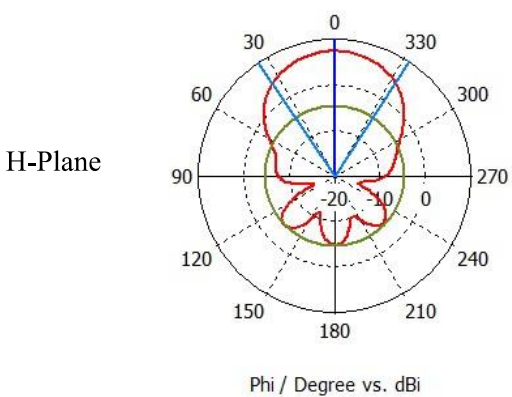

Farfield Realized Gain Abs (Theta $=90)$

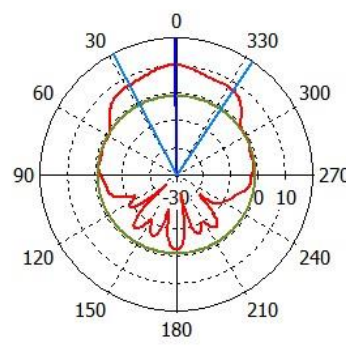

Phi / Degree vs. dBi

$7 \mathrm{GHz}$

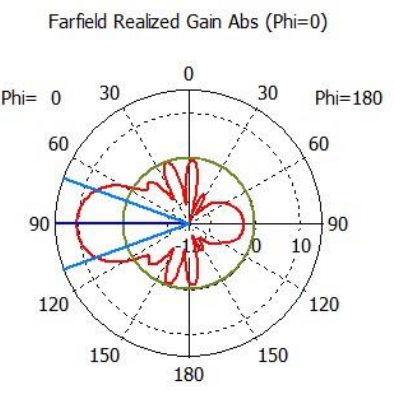

Theta / Degree vs. dBi
Farfeld Realized Gain Abs (Theta $=90$ )

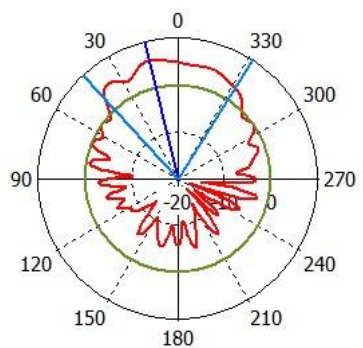

Phi / Degree vs. dBi

$11 \mathrm{GHz}$

Farfield Realized Gain Abs (Phi $=0)$

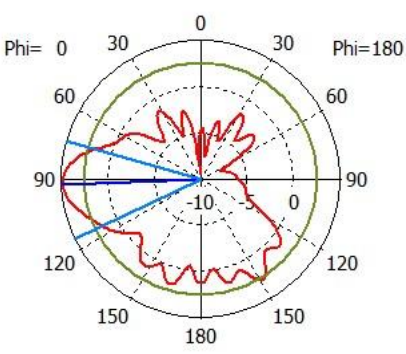

Theta / Degree vs. dBi

Single Slot Vivaldi Antenna

Figure 5. Simulated radiation patterns of single slot vivaldi antenna at three different frequencies. 
Farfield Realized Gain Abs (Theta=90)

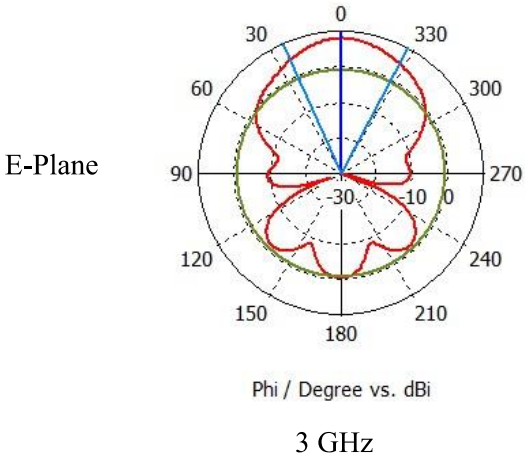

Farfield Realized Gain Abs (Phi=0)

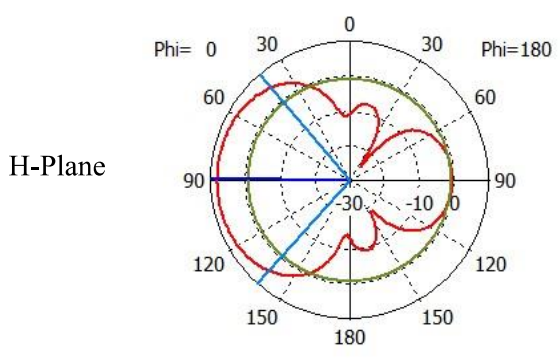

Theta / Degree vs. dBi
Farfield Realized Gain Abs (Theta $=90$ )

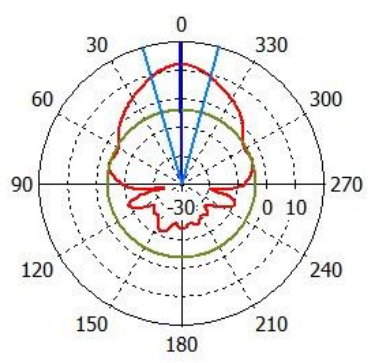

Phi / Degree vs. dBi

$7 \mathrm{GHz}$

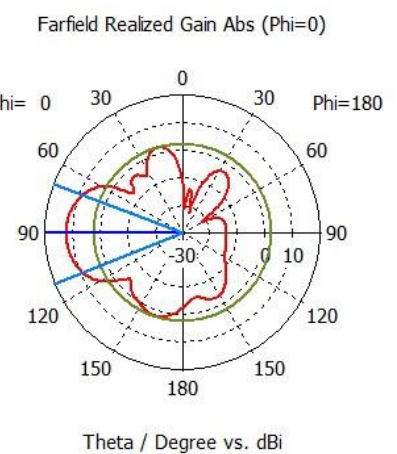

Double Slot Vivaldi Antenna
Farfield Realized Gain Abs (Theta $=90$ )

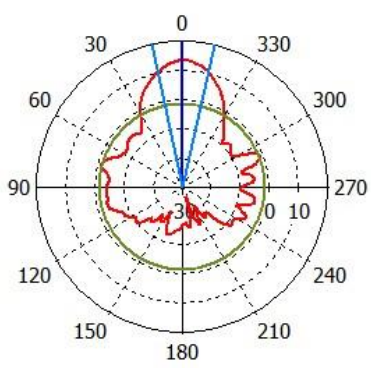

Phi / Degree vs. dBi

$11 \mathrm{GHz}$

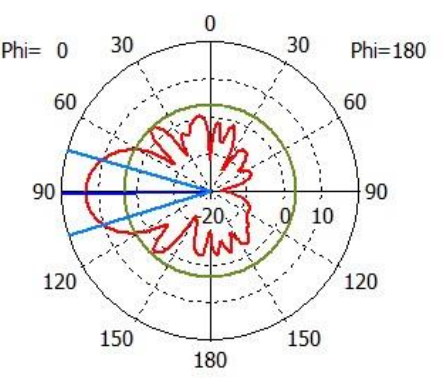

Theta / Degree vs. dBi

Figure 6. Simulated radiation patterns of double slot vivaldi antenna at three different frequencies.
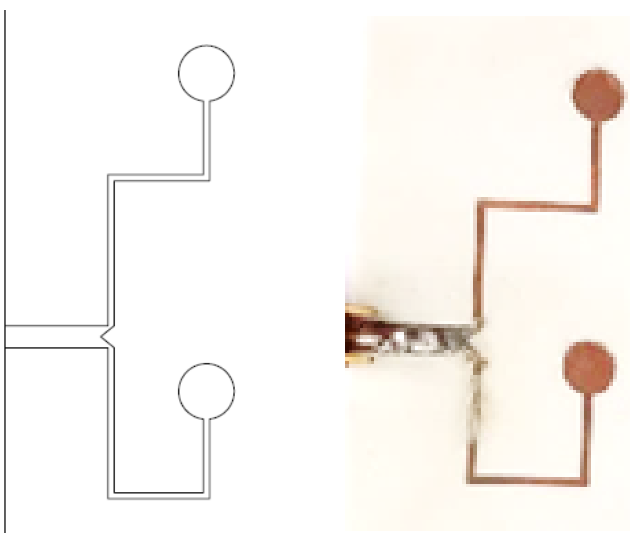

Figure 7. Difference between simulated and fabricated tuning stubs.

TABle 2 Simulated Gain OF Single Slot AND Double Slot ANTENNA

\begin{tabular}{|c|c|c|}
\hline $\begin{array}{c}\text { Frequency } \\
(\mathbf{G H z})\end{array}$ & $\begin{array}{c}\text { Single slot } \\
(\mathbf{d B i})\end{array}$ & $\begin{array}{c}\text { Double slot } \\
(\mathbf{d B i})\end{array}$ \\
\hline 3 & 7.34 & 7.92 \\
\hline 4 & 8.8 & 11.4 \\
\hline 5 & 9.76 & 11.1 \\
\hline 6 & 10.5 & 12.5 \\
\hline 7 & 10.1 & 12 \\
\hline 8 & 9.05 & 11.9 \\
\hline 9 & 9.43 & 13 \\
\hline 10 & 8.85 & 13.3 \\
\hline 11 & 5.87 & 13.3 \\
\hline & \multicolumn{2}{|}{} \\
\hline
\end{tabular}

From these results, it can be concluded that there is a significant increase in gain performance by using the proposed method compared to the conventional one. From the increase in gain, it can be known that the higher the frequency, the greater the gain produced.

\section{CONCLUSION}

Based on the results of the simulation of the Vivaldi double slot antenna with corrugated edges and semicircle director, it can be determined that the results have already fulfilled the required parameters, with operating frequencies from $3.1 \mathrm{GHz}$ to $10.6 \mathrm{GHz}$, and $-10 \mathrm{~dB}$ bandwidth of $7.5 \mathrm{GHz}$. The addition of corrugated edges and a semicircle director to the Vivaldi double slot antenna results in a gain that is equal to or greater than that of conventional Vivaldi, single-slot, or double slot antennas. The proposed antenna also has a good increase in gain, where the higher the frequency, the gain is increased. However, there is a slight discrepancy in the operating frequency of the antenna prototype that is mainly caused by imperfect fabrication. The operating frequencies of the fabricated antenna are $3.5 \mathrm{GHz}-3.75$ $\mathrm{GHz}$ and $4.25-10.89 \mathrm{GHz}$. Regarding its broadband characteristic and excellent gain performance, all of these results imply that the proposed antenna is potential for microwave imaging applications.

\section{ACKNOWLEDGMENT}

This work was supported by Indonesian Institute of Sciences (LIPI) through research project entitled: "Development of Electromagnetic Components for 
Medical Imaging Applications". This work is also partially supported by the PRN BOPTN program from the Indonesian Ministry of Education, Culture, Research, and Technology.

\section{REFERENCES}

[1] J. J. Estrada, "Microwave object detection and image reconstruction with a synthetic circular aperture", Master Thesis, University of Oslo, Oslo, Norway, 2018.

[2] D. A. Kharisma, "Radiasi ionizing dan non ionizing", Universitas Jember, Jember, Indonesia, 2014.

[3] D. Achmad Alwan Arseno and A. D. Setiawan, "Perancangan dan realisasi antena mikrostrip dengan frekuensi 1,4-4,4 Ghz untuk ground penetrating radar," e-Proceeding of Engineering, vol. 6, pp. 988-994, 2019.

[4] Y.-W. Wang, G.-M. Wang and B.-F. Zong, "Directivity improvement of vivaldi antenna using double-slot structure," IEEE Antennas and Wireless Propagation Letters, vol. 12, pp. 1380-1383, October 2013.

[5] C. Uyanik, A. O. Ertay, S. Dogu, I. Akduman and H. Sahinturk, "A coplanar vivaldi antenna design with improved frequency response for microwave breast imaging," in IEEE Conference on Antenna Measurements and Applications (CAMA), Syracuse, New York, 2016.

[6] L. C. Paul, M. N. Hossain, M. M. U. Rashid, M. M. Mowla, M. Z. Mahmud and M. T. Islam, "A novel miniaturized coplanar waveguide fed tapered slot ultra wide band vivaldi antena for microwave imaging applications," in 10th International
Conference on Computing, Communication and Networking Technologies (ICCCNT), Kanpur, 2019.

[7] M. Yumnisari, B. S. Nugroho and P. Daud, "Perancangan dan simulasi antena mikrostrip ultra wideband untuk deteksi kanker payudara," in Seminar Nasional Inovasi Dan Aplikasi Teknologi Di Industri, Malang, 2017.

[8] M. A. Saputra, H. Wijanto and Y. Wahyu, "Antena vivaldi antipodal sirkular ultra wide-band (UWB) untuk radar tembus tembok," in Seminar Nasional Sains dan Teknologi, Jakarta, 2018.

[9] M. T. Islam, M. Z. Mahmud, N. Misran, J. Takada and M. Cho, "Microwave breast phantom measurement system with compact side slotted directional antenna," IEEE Access, vol. 5, pp. 53215330, April 2017.

[10] F. Oktafiani, Y. S. Amrullah, Y. P. Saputera, Y. Wahyu and Y. N. Wijayanto, "Analysis of corrugated edge variations on balanced antipodal Vivaldi antennas," in 2015 International Conference on Radar, Antenna, Microwave, Electronics and Telecommunications, Bandung, 2015.

[11] Y. Zhang, E. Li, C. Wang and G. Guo, "Radiation enhanced vivaldi antenna with double-antipodal structure," IEEE Antenna and Wireless Propagation Letters, vol. 16, pp. 561-564, July 2016. 